\section{Response to: 'Eosinophilic granulomatosis with polyangiitis can manifest lacrimal and salivary glands swelling by granulomatous inflammation: a potential mimicker of IgG4- related disease' by Akiyama et al}

In their insightful correspondence, Akiyama et $a l^{1}$ focus on a peculiar feature of eosinophilic granulomatosis with polyangiitis (EGPA), that is, the involvement of salivary and lacrimal glands, which mimics the Mikulicz disease, a common manifestation of IgG4-related disease (IgG4-RD). Given that EGPA shows high serum IgG4 levels (particularly in its active phases), ${ }^{2}$ and that IgG4-RD often features allergy, eosinophilia and respiratory tract involvement, the differential diagnosis between these two disorders may be challenging. The observation that patients with EGPA can present with Mikulicz-like salivary and lacrimal gland involvement enhances the difficulty in the differential diagnosis with IgG4-RD. In the reported cases, however, histology of the affected glands consistently disclosed eosinophilic granulomas, a hallmark of EGPA.

It is interesting to note that diseases with such a different clinical course and histology can have similar features. EGPA and IgG4-RD certainly share some pathobiological mechanisms, such as T helper 2 polarised and regulatory responses, which may be responsible for IgG4 skewing and eosinophil proliferation; such responses may as well promote fibrosis, which is characteristic of IgG4-RD, ${ }^{3}$ but also occurs in EGPA, particularly in the airways and the myocardium. ${ }^{4}$ However, the complex overlap between IgG4-RD and EGPA is also due to the fact that both conditions encompass a wide range of disease subsets, whose pathogenesis and clinical features may differ. In a recent large-scale study, IgG4-RD showed distinct clinical clusters with differences in organ involvement and IgG4 levels: for instance, patients with Mikulicz had the highest IgG4 responses, while IgG4 were lower in those with predominant retroperitoneal or aortic disease. ${ }^{5}$ Also, allergy or atopy features appear to be limited to a subset of patients with IgG4-RD. ${ }^{6}$ Likewise, EGPA recognises two main subphenotypes, one predominantly vasculitic, characterised by antineutrophil cytoplasmic antibody (ANCA) positivity and the frequent occurrence of peripheral neuropathy, glomerulonephritis and purpura, and one predominantly eosinophilic, usually ANCA-negative and with more frequent involvement of the myocardium and the gastrointestinal tract. Such subsets also have distinct genetic signatures, the former being associated with $H L A-D Q$ and the latter with variants of genes involved in mucosal responses such as GPA33. ${ }^{7}$

The heterogeneity of the clinical spectra of IgG4-RD and EGPA and the likely pathogenic differences between their subsets may account for the partial overlap between these two syndromes. Once their underlying mechanisms are dissected and new diagnostic biomarkers are identified, we will probably better understand why they overlap and how we can better address the differential diagnosis.
Augusto Vaglio $\odot{ }^{1,2}$ Federica Maritati, ${ }^{3}$ Jochen Zwerina ${ }^{4}$

1 Department of Biomedical Experimental and Clinical Sciences "Mario Serio", University of Florence, Firenze, Italy

${ }^{2}$ Nephrology Unit, Meyer Children's Hospital, Firenze, Italy

${ }^{3}$ Nephrology, Dialysis and Transplant Unit, University Hospital "Ospedali Riuniti" of Ancona, Ancona, Italy

${ }^{4}$ Ludwig Boltzmann Institute of Osteology at Hanusch Hospital of Österreichische Gesundheitskasse (ÖGK) and Research Funds of the Austrian Workers

Compensation Board (AUVA), 1st Medical Department, Hanusch Hospital, Wien, Austria

Correspondence to Dr Augusto Vaglio, University of Florence, Firenze 50139, Italy; augusto.vaglio@virgilio.it

Handling editor Josef S Smolen

Contributors AV wrote the manuscript, and FM and JZ contributed to critical revision.

Funding The authors have not declared a specific grant for this research from any funding agency in the public, commercial or not-for-profit sectors.

Competing interests None declared.

Patient and public involvement Patients and/or the public were not involved in the design, or conduct, or reporting, or dissemination plans of this research.

Patient consent for publication Not required.

Provenance and peer review Commissioned; internally peer reviewed.

(C) Author(s) (or their employer(s)) 2020. No commercial re-use. See rights and permissions. Published by BMJ.

\section{Check for updates}

To cite Vaglio A, Maritati F, Zwerina J. Ann Rheum Dis Epub ahead of print: [please include Day Month Year]. doi:10.1136/annrheumdis-2020-218174

Received 7 June 2020

Accepted 8 June 2020

\section{S Linked}

- http://dx.doi.org/10.1136/annrheumdis-2020-218124

Ann Rheum Dis 2020;0:1. doi:10.1136/annrheumdis-2020-218174

ORCID iD

Augusto Vaglio http://orcid.org/0000-0002-3814-9172

\section{REFERENCES}

1 Akiyama M, Kaneko Y, Takeuchi T. Eosinophilic granulomatosis with polyangiitis can manifest lacrimal and salivary glands swelling by granulomatous inflammation: a potential mimicker of IgG4-related disease. Ann Rheum Dis. doi:10.1136/ annrheumdis-2020-218124.

2 Vaglio A, Strehl JD, Manger B, et al. IgG4 immune response in Churg-Strauss syndrome. Ann Rheum Dis 2012;71:390-3.

3 Corradi D, Nicastro M, Vaglio A. Immunoglobulin G4-related disease: some missing pieces in a still unsolved complex puzzle. Cardiovasc Pathol 2016;25:90-2.

4 Trivioli G, Terrier B, Vaglio Aet al. Eosinophilic granulomatosis with polyangiitis: understanding the disease and its management. Rheumatology 2020;59:iii84-94.

5 Wallace ZS, Zhang Y, Perugino CA, et al. Clinical phenotypes of IgG4-related disease: an analysis of two international cross-sectional cohorts. Ann Rheum Dis 2019;78:406-12.

6 Della Torre E, Mattoo H, Mahajan VS, et al. Prevalence of atopy, eosinophilia, and IgE elevation in IgG4-related disease. Allergy 2014;69:269-72.

7 Lyons PA, Peters JE, Alberici F, et al. Genome-wide association study of eosinophilic granulomatosis with polyangiitis reveals genomic loci stratified by ANCA status. Nat Commun 2019;10:5120. 